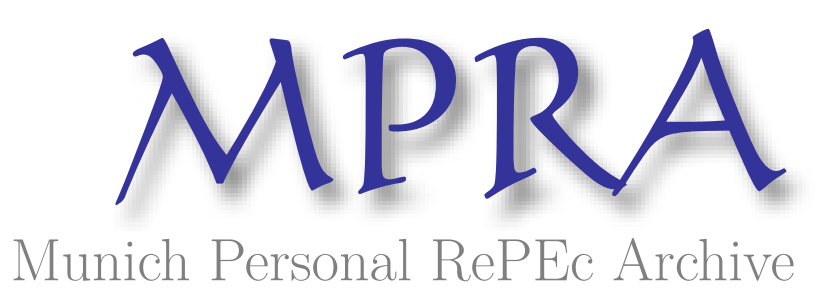

\title{
Will the Market Get it Right? The Placing of New Power Plants in Germany
}

Dietrich, Kristin and Leuthold, Florian and Weigt, Hannes

April 2009

Online at https://mpra.ub.uni-muenchen.de/65653/

MPRA Paper No. 65653, posted 18 Jul 2015 10:00 UTC 


\title{
Electricity Markets Working Papers \\ WP-EM-32
}

\author{
Will the Market Get it Right? \\ The Placing of New Power Plants in Germany
}

Kristin Dietrich, Florian Leuthold, Hannes Weigt

April 2009

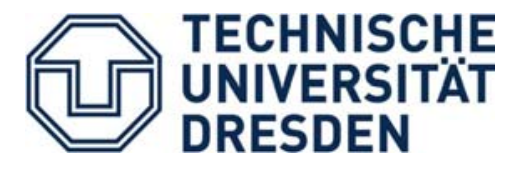

Dresden University of Technology

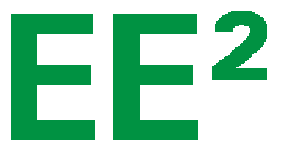

Chair for Energy Economics and Public Sector Management 


\title{
Will the Market Get it Right? The Placing of New Power Plants in Germany
}

\author{
Kristin Dietrich $^{1}$, Florian Leuthold, Hannes Weigt ${ }^{2}$
}

\section{Corresponding author:}

Florian Leuthold

Dresden University of Technology

Faculty of Business and Economics

Chair of Energy Economics and Public Sector Management

01069 Dresden, Germany

Phone: +49-(0)351-463-39764

Fax: $\quad+49-(0) 351-463-39763$

florian.leuthold@tu-dresden.de

\section{Abstract:}

This paper applies ELMOD, an economic-engineering model of the European electricity market to the issue of optimal investment placing of generation capacity in Germany under different market integration scenarios. The model is formulated as cost minimization approach. We conduct a scenario analysis comparing different rules for power plant placing in a national, a market-coupling and an integrated EU market approach. We find that there are great benefits for consumers and producers if taking into account network conditions and cross border congestion in generation location planning. Moreover a change from national planning to an integrated market planner perspective shows even more improvements in prices and network utilization.

Key words: $\quad$ electricity, investment, generation, Germany

JEL-code: $\quad$ L94, L51, D61

\footnotetext{
1 Comillas University of Madrid, School of Engineering (ICAI), Institute for Research in Technology (IIT), kristin.dietrich@iit.upcomillas.es

${ }^{2}$ Dresden University of Technology, Faculty of Business and Economics, Chair of Energy Economics and Public Sector Management, hannes.weigt@tu-dresden.de
} 


\section{Introduction}

Over ten years after the implementation of the European Directive 96/92/EC seeking to restructure the electricity market and create competition, Europe has still a long way to go towards an integrated single European market. Obstacles to liberalization, lacking investments in cross-border transmission capacity, only gradually converging market designs and other issues have made the integration process a slow one, and the success is far from being achieved. Nonetheless, there is still some momentum in the restructuring process, as evidenced by the European Energy Package of 2009, and attempts to incite member states to pursue the route of integration and market reforms.

The process of liberalization brought up several new fields for research and discussions in electricity markets. Particularly the interaction of short-term and long-term aspects is under intense discussion. The short-term considerations focus on the efficient management of the existing infrastructure which falls under the term efficient congestion management. The literature on congestion management is comprehensive. It includes the discussion about zonal or nodal prices (Hogan, 1992, 1999; Ding \& Fuller, 2005) and modifications thereof as proposed in the European context (e.g. Ehrenmann \& Smeers, 2005). In contrast to the developments in the USA, where nodal pricing has become integral part of a standard market design, Europe still struggles to find the right procedure in order to integrate several national electricity markets within a single market. Different regions decided to implement different approaches. Ehrenmann and Smeers (2005) provide a useful overview over the debate that is still valid. Basically, there are three approaches: market coupling, market splitting, and explicit coordinated auctions. Market coupling and market splitting are both a form of zonal pricing. The term market coupling describes the process of jointly coordinating geographically separated electricity markets. An example for a market coupling is the coordination of the power exchanges of Belgium, France, and the Netherlands (Belpex, 2009). In the case of market splitting a single electricity market is already in existence which can be split up into several submarkets (normally in case of congestion). An example for market splitting is the Nordpool market in Scandinavia (Nordpool, 2009). In zonal and nodal pricing markets, the traded commodity is electrical energy. The energy price implicitly reflects all associated marginal costs (e.g. production and losses) and capacity rents (e.g. production and transmission). In the European context, those types of market designs are also referred to as implicit auctions (Meeus, 2006). In contrast to implicit auctions, within an explicit auction, transmission and energy bids have to be placed separately. Flow based explicit coordinated auctions are currently applied in Central East Europe (CEE).

There is an ongoing debate about whether the market structures based on the congestion management methods described above are efficient in a long-term perspective which relates to the topic of investment incentives. Concerning investment issues one can distinguish generation and transmission investments. Pokharel and Ponnambalam (1997) develop a straightforward cost minimization model in order to analyze the planning for power plant expansion under deterministic and stochastic demand. They find that under the assumption of a deterministic demand, the installed capacity would be higher 
than if stochasticity in demand is taken into account. Ishii and Yan (2004) analyze the generation investment behavior in the US electricity industry between 1996 and 2000 focusing on regulatory uncertainty. They apply a real options approach and find that under regulatory uncertainty companies have incentives to delay investments. Murphy and Smeers (2005) focus on the effects of imperfectly competitive markets on generation investment decisions. They find that the complexity of the investment decision process increases along with the complexity of the electricity market structure. ${ }^{3}$ Smeers (2006) is concerned with the discrete nature of generation location decisions and suggests a multi-part tariff in the context of the regional market within Europe. He develops a model that is able to calculate economically efficient locational prices which are cost-reflective and allow a separation of short- and long-term prices. However, these prices are discriminatory. He concludes that the three criteria economic efficiency, cost reflectiveness and non-discrimination cannot be achieved at the same time and some trade-off has to be made. Zoettl (2008) models optimal investment decisions of strategic firms in a liberalized electricity market. He concludes that under imperfect competition firms have strong incentives to invest into capacities with low marginal costs taking into account the effect of the generation expansion on the output decision of the competitor. At the same time, the total capacities are chosen too low from a welfare point of view.

However, the aspects generation and transmission influence each other in the electrical power sector. Hence, there is some literature on generation investment that includes the transmission aspect of electrical networks. Hogan (1992) develops the idea of financial instruments that help to incorporate physical network congestion in an economic context. Bushnell and Stoft (1996) state that these transmission congestion contracts (TCCs) allow hedging of locational price risks and, thus, support generation investments. ${ }^{4}$ Recent approaches try to define an electricity market design that incorporates an efficient congestion management design and sufficient investment incentives (e.g. Joskow, 2008). Pérez-Arriaga and Olmos (2006) examine the compatibility of investment signals in transmission and generation. They emphasize that agents should face the real network cost incurred by their location decision and propose to apply beside the nodal energy price a locational transmission tariff, which should serve as long-term signal for network users. They provide criteria to how such a nodal transmission tariffs should be determined. Rious et al. (2008) analyze the impact of a two-part tariff in order to manage electricity networks efficiently in a short- and in the long-run perspective. They find that a joint implementation of nodal pricing and the average participation tariff is the best combination to coordinate the generation and transmission investments as efficiently as possible. However, the optimal set of generation and transmission investments may not be carried out because of transmission lumpiness. ${ }^{5}$

In this paper we focus on scenarios for generation investment in the German electricity market. We analyze where in the current scheme new investment in generation is most likely to take place and

\footnotetext{
${ }^{3}$ Murphy and Smeers (2005) do not focus on policy conclusions but provide an in-depth discussion of algorithmic issues arising from different market structure assumptions.

${ }^{4}$ The terms TCC and financial transmission right (FTR) are interchangeable (Joskow and Tirole, 2005).
} 
compare these results to an optimal investment pattern taking into account network capacities. The analysis is carried out for different assumptions regarding market representation including a national focus on Germany, a market coupling setting, and a fully integrated European market. The results indicate that an approach limited to a national viewpoint is insufficient in accounting for impacts from neighboring countries and thus results in wrong price signals. We show that an allocation of power plants with respect to network restrictions leads to a more efficient utilization of available capacities and thus lower market prices.

The remainder of this paper is structured as follows: Section 2 presents the model formulations and the data used to derive our results. We apply ELMOD, a model of the European electricity market, and include an extension algorithm to obtain welfare optimal plant locations. The analysis focuses on Germany with an approximation of the surrounding networks. Section 3 presents scenarios and results. We apply three different market scenarios and three different extension methods. Section 4 provides the conclusions.

\section{Model formulations and data}

Our analysis is based on ELMOD, a model of the European electricity market including the physical transmission network. The model was developed in order to analyze various issues of market design, congestion management, and investment decisions (Leuthold et al., 2008). ELMOD is a bottom-up model combining electrical engineering and economics: its objective function is welfare maximization, subject to technical constraints. We adjust the basic model formulation in order to allow for flexible power plant investment patterns.

\subsection{Basic model formulation}

The basic welfare maximization model formulation is transferred into a total cost (TC) minimizing approach taking into account that: 1.) at each node $n$ the sum of demand $q_{n t}$ and the total generation $g_{n s t}$ of all plants $s$ have to equal the net injection $i_{n t}$,2.) power plants $s$ can not generate more than their maximum capacities $g^{\max }$ and not less than their minimum necessary generation limit $g^{\min }$ in case they are running (viz. variable $o n=1$ ), otherwise they have to turn offline (viz. variable $o n=0$ ), and 3.) power flows $P$ on a line $l$ have to remain within the power flow limit $P^{\max }$. All these constraints have to hold in each time period $t$.

$$
\begin{array}{ll}
\min _{g_{n s t}, i_{n t}, o n_{n s t}, P_{l t}}\{T C & \left.=\sum_{n, s, t} c_{n s} g_{n s t}\right\} \\
& \sum_{s} g_{n s t}-q_{n t}-i_{n t}=0 \forall n, t \quad \text { energy balance constraint }
\end{array}
$$

\footnotetext{
${ }^{5}$ Also, Rious et al. (2008) used a two-node network which might not be capable to capture the full impact of physical loop flows.
} 


$$
\begin{array}{ll}
\text { on }_{n s t} g_{s}^{\min } \leq g_{n s t} \leq \text { on }_{n s t} g_{s}^{\max } \forall n, s, t & \text { generation constraint } \\
\left|P_{l t}\right| \leq P_{l}^{\max } \forall l, t & \text { line flow constraint }
\end{array}
$$

The actual power flow calculation is based on a DC load flow approach as presented in Schweppe et al. (1988) and Stigler and Todem (2005). We do not conduct a full (n-1)-contingency calculation when obtaining the optimal dispatch. However, a $20 \%$ transmission reliability margin is considered. Thus, no line within the modeled grid will be stressed with more than $80 \%$ of their thermal capacity limit. The demand $q$ is fixed and a time-frame of 12 time periods $t$ is considered that is adjusted to resemble an average year (see Section 2.3). The model is coded as mixed integer problem (MIP) in GAMS.

\subsection{Modeled approaches for power plant placing}

We compare a set of given projected plant extensions (see Section 3.1) to extensions determined by our model. Therefore, we adjust the basic model formulation to allow for a flexible plant location. We assume a benevolent planner approach in which the projected plants are located in order to maximize social welfare (i.e. minimize total costs). The generation location becomes an endogenous variable and is incorporated into the model formulation. We provide a new set of variables $g^{\text {new }}$ for plant extensions. The locational choice is indicated by a binary variable $b_{n e}$ which states if a new plant $e$ is built at a specific node $n$. The dispatch of the new plants is defined as $g^{\text {new }}$ and like normal generation can be used to satisfy demand:

$$
\sum_{s} g_{n s t}+\sum_{e} g_{n e t}^{n e w}-q_{n t}-i_{n t}=0 \forall n, t \quad \text { new energy balance constraint }
$$

The new plants are subject to a capacity constraint:

$$
b_{n e} g_{e}^{\min } \leq g_{n e t} \leq b_{n e} g_{e}^{\max } \forall n, e \quad \text { extension generation constraint (6) }
$$

The total number of new plants is restricted according to the number of new plants projected $E$

$$
\sum_{n, e} b_{n e} \leq E \quad \text { extension limit }
$$

Thus, if at a specific node $n$ additional generation is needed to satisfy demand (equation 5), capacity has to be build up at that node by setting $b_{n e}$ to 1 (equation 6), which in turn reduces the number of available new generation units to be allocated (equation 7). The objective function (equation 1) is adjusted by the generation costs of the new units $c^{\text {new }}$ :

$$
\min _{g_{n s t}, i_{n t}, o n_{n s t}, P_{l t}, b_{n e}, g_{n e t}^{\text {new }}}\left\{T C^{\text {new }}=\sum_{n, s, t} c_{n s} g_{n s t}+\sum_{n, e, t} c_{n e}^{n e w} g_{n e t}^{n e w}\right\}
$$

Thus the new plants will be placed according to the costs objective taking into account network independences. Further specifications as which subset of nodes $n$ is eligible for the extension process depends on the conducted scenario (see Section 3.1). 


\subsection{Data}

The modeled network is based on the European extra high voltage grid (UCTE, 2004; VGE, 2006) with a focus on Germany covering a total of 365 substation and 586 lines (Figure 1). We assume three different line types, one for each voltage level $(380 \mathrm{kV}, 220 \mathrm{kV}, 110 \mathrm{kV})$. The line parameters (maximum thermal limit, line resistance and line reactance) are based on Fischer and Kießling (1989). As power flows in neighboring countries can influence prices in Germany, a simplified approximation of the surrounding European grid is implemented. All cross-border lines between countries are modeled according to their length and voltage level and are connected to a single country node concentrating all demand and generation of the country with auxiliary country tie-lines of unlimited capacity. This approach allows accounting for cross border congestion problems but neglects inner country congestion in neighboring countries.

Generation is divided into eight plant types. ${ }^{6}$ Wind capacity is addressed separately as an external parameter that lowers demand at a specific node. Power plant capacities are based on VGE (2006). Each plant $s$ is assigned to one node $n$. Thus nodes can have more than one plant of the same or different type. In total about 300 plants are allocated to 150 nodes in the system. We do not account for start-up costs and ramping constraints. Generators are assumed to be price takers bidding their full capacities at marginal generation costs. Costs are estimated using fuel type and price, power plant efficiency, and emissions. Input prices are assumed to represent average values for 2007 (Bafa, 2008). As electricity demand varies during a day and season our approach consists of 12 reference periods $t$ that resemble typical load situations during a year. The influencing factors are: season, wind input and time of day (Table 1). The periods are divided into a summer and winter term which has an impact on the general load level as demand is higher during winter months. The two seasons are furthermore divided into a low and high wind input segment. The wind input is defined via historic wind speed data for 8 stations in Germany (DWD, 2005). The low wind input segment consists of the 75\% lowest wind speed hours during the season and the high wind input segment of the remaining $25 \%$. The actual wind generation is determined by taking the average wind speed during the segments as proxy. A total of about $27 \mathrm{GW}$ is assumed to be installed in 2012 in Germany (Dena, 2005). Load is divided into an off-peak (8pm - 8am), a peak (12am, 5pm - 6pm) and a mid load segment. The segments are weighted such that they represent an average year based on historic demand (UCTE, 2006) and wind input data (DWD, 2005).

The models differ in the location of newly installed plant capacities. Furthermore, demand and generation of neighboring countries is treated differently (see section 3.1). The cost assumptions for Germany, the time segments, and the modeled network are constant in all market representation scenarios.

\footnotetext{
${ }^{6}$ The eight types are: nuclear, lignite, coal, oil and gas steam plants, combined cycle gas turbines plants, hydro, pump storage and combined heat power plants.
} 
Table 1: Period characteristics

\begin{tabular}{|c|c|c|c|c|c|c|c|c|c|c|c|c|}
\hline Period & $\mathbf{t}_{1}$ & $\mathbf{t}_{2}$ & $\mathbf{t}_{3}$ & $\mathbf{t}_{4}$ & $\mathbf{t}_{5}$ & $\mathbf{t}_{6}$ & $\mathbf{t}_{7}$ & $\mathbf{t}_{8}$ & $t_{9}$ & $\mathbf{t}_{10}$ & $t_{11}$ & $\mathbf{t}_{12}$ \\
\hline Season & \multicolumn{6}{|c|}{ Winter } & \multicolumn{6}{|c|}{ Summer } \\
\hline $\begin{array}{l}\text { Wind } \\
\text { input }\end{array}$ & & Low & & & High & & & Low & & & High & \\
\hline Load & $\begin{array}{l}\text { Off- } \\
\text { peak }\end{array}$ & Mid & Peak & $\begin{array}{l}\text { Off- } \\
\text { peak }\end{array}$ & Mid & Peak & $\begin{array}{l}\text { Off- } \\
\text { peak }\end{array}$ & Mid & Peak & $\begin{array}{l}\text { Off- } \\
\text { peak }\end{array}$ & Mid & Peak \\
\hline $\begin{array}{l}\text { Weight } \\
{[\%]}\end{array}$ & 18.75 & 14.06 & 4.69 & 6.25 & 4.69 & 1.56 & 18.75 & 14.06 & 4.69 & 6.25 & 4.69 & 1.56 \\
\hline
\end{tabular}

Figure 1: Modeled network

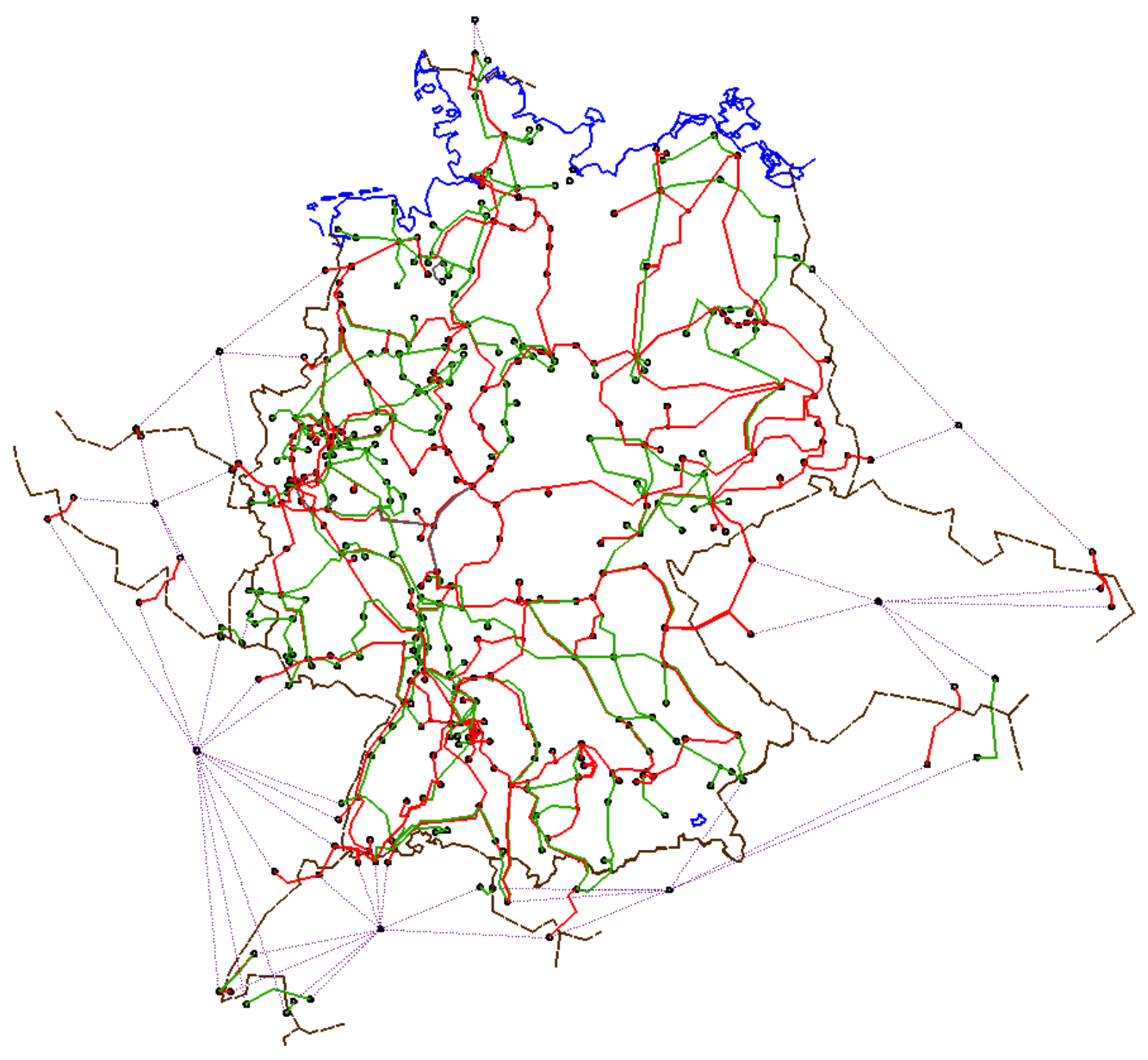

\section{Scenarios and Results}

\subsection{Scenarios}

In total we conduct three different cases of power plant extension: the 2007 benchmark case, the 2012 projection considered as base case, and the benevolent planner approach for 2012 considered as welfare case. Furthermore we apply three different approaches for market representation: a national approach in which only Germany is considered without cross border transactions (German scenario); 
a multi national approach including generation and demand of neighboring countries (Market coupling scenario); and an integrated market approach (EU scenario).

The first scenario represents the existing view that electricity markets are national markets and project planning stops at borders. As neighboring countries are not accounted for in that scenario, plant extensions can only take place in Germany. The second scenario assumes that project planners know that markets interact and plants located in Germany can be utilized to satisfy foreign demand needs. However, the national perspective prevails as the actual locational choice is still limited to national borders. We therefore restrict the endogenous approach to locate new plants only within Germany. The last scenario represents the objective of the European commission to establish a single integrated market. It differs from the market coupling scenario only in the allowed locations for new power plants, now including neighboring countries. This resembles a multinational planning perspective where national borders are no obstacle any more. For the market coupling and EU scenario electricity demand and generation from other countries is taken into account, in the German scenario they are neglected. The network representation remains the same in all scenarios including the approximated representation of the surrounding grid.

The time-frame for extensions is 2012 whereas only plants that are scheduled to be finished in 2010 to 2012 are considered within the locational analysis. Plants that are projected before 2010 are considered to be fixed with respect to their locations. Furthermore, hydro, pump storage, and lignite plants are assumed to be restricted to specific locations due to water or fuel availability. Thus, only coal and combined cycle gas turbine (CCGT) power plants are analyzed in detail. ${ }^{7}$ Power plant extensions in neighboring countries that are included in the data set are not taken into consideration for the locational analyses. The scheduled extensions for Germany are based on Knight (2006). A total of 12 new coal plants and one CCGT plant are projected to be finished till 2012. Furthermore, $7 \mathrm{GW}$ are planned to go online before 2010 in Germany and about $15 \mathrm{GW}$ are added in neighboring countries. ${ }^{8}$ Table 2 summarizes the projected schedule.

For the 2007 benchmark case new plants are excluded from the calculation in order to obtain a reference price level. For the base case we include the extensions as projected by Knight (2006). These plant locations are mainly driven by fuel availability, demand, and availability of grid connections as the German electricity wholesale market applies a uniform pricing approach which does not send any locational price signals. The majority of the new plants are located in the urban area of the Ruhr and the North-West coastline. We assume that this schedule does not represent the welfare optimum as interdependences of load, generation, and network are not taken into account.

For the welfare case we restrict that only one new plant can be built at any given node within Germany. Thus, a clustering of power plants at single nodes is not possible. For the EU scenario we allow that more than one plant can be build at the approximated neighboring countries nodes but still only one plant at each node within Germany.

\footnotetext{
${ }^{7}$ There are neither open cycle gas turbines nor oil/gas fired steam plants projected in Germany.
} 
Table 2: Projected power plant capacities until 2012

\begin{tabular}{lcccc}
\hline & Lignite & Coal & CCGT & Other \\
\hline Germany before 2010 & $2.10 \mathrm{GW}$ & $0.27 \mathrm{GW}$ & $4.54 \mathrm{GW}$ & - \\
Germany 2010-2012 & $0.67 \mathrm{GW}$ & $10.56 \mathrm{GW}$ & $0.80 \mathrm{GW}$ & $0.12 \mathrm{GW}$ \\
Neighboring Countries & $0.66 \mathrm{GW}$ & $3.50 \mathrm{GW}$ & $8.24 \mathrm{GW}$ & $1.29 \mathrm{GW}$ \\
\hline
\end{tabular}

\subsection{Results and Comparison}

First the Germany market scenario is calculated. ${ }^{9}$ While excluding import and export possibilities, the average price level in the 2007 benchmark case ranges from 40 to $60 € / \mathrm{WMh}$ with lower prices in East and higher prices in South Germany. On average, the daytime price level is about $5 € / M W h$ higher. However, the geographical price distribution does not change. The eastern grid is still only linked to the western at three interconnections resulting in a price separation between East and West Germany if locational pricing were applied. A large price gap between Thuringia and Bavaria can be observed which is due to network congestion. The corresponding link is planned to be upgraded until 2012 (Dena, 2005). With the projected network extensions and new power plants until 2012 in the base case the average price level in Germany converges towards 40 to $45 € / \mathrm{MWh}$ and is about $10 \%$ lower than in 2007. The daytime price level is about $2 € / \mathrm{WMh}$ higher than the average price (Table 3 ) with higher prices in South Germany. If plant locations are obtained endogenously in the welfare case the price level drops an additional $1 € / \mathrm{MWh}$ for both the average and the daytime prices. Furthermore, the market separation between North and South Germany is reduced.

Comparing the plant locations between the projected and the endogenously chosen sites shows some similarities. A fraction of the welfare-maximizing new plants is also placed at the northern coast line and close to the demand center "Ruhrgebiet" (Ruhr area) in West Germany. However, more plants are allocated near the south-western border to France and Switzerland, and two plants are located in northern Bavaria close to the interconnection to East Germany. The latter allows a better utilization of the inner German interconnection as they produce counter flows for the large share of base load, hydro pump storage, and wind energy transmitted from East Germany towards South Germany. The plants close to the French and Switzerland borders are located in a highly populated area with a large share of residential and industrial demand.

If neighboring countries are included into the market representation within the Market coupling approach the results differ significantly. In the 2007 benchmark case the average price level is about $5.5 € / \mathrm{MWh}$ higher and daytime prices are $10 € / \mathrm{MWh}$ higher than in the Germany market scenario. The general price increase results from two effects: 1.) a fraction of the German power plant portfolio is now utilized to satisfy demand in neighboring countries resulting in higher prices for domestic demand in Germany; 2.) increased generation output and demand result in increased power transmission resulting in congestion causing larger price divergence. East Germany shows lower prices than West

\footnotetext{
${ }^{8}$ The extension amount is based on Brandstetter (2007), CEZ (2007) Slingerland et al. (2006), House (2004), VSE (2006), Elia (2008).

${ }^{9} \mathrm{~A}$ graphical representation of the obtained price levels and plant locations is provided in Annex I.
} 
Germany. However, the high price region moves from South Germany to North-West Germany which is due to congestion at the border to and within the Benelux. The base case extension for 2012 results in a price reduction of about $10 € / \mathrm{MWh}$ on average and more than $15 € / \mathrm{MWh}$ for daytime prices compared to the benchmark case (Table 3). Like in the Germany market scenario the prices within Germany tend to equalize. However, congestion problems still remain, particularly at the Benelux borders. In the welfare extension case an additional price reduction of about $1 € / \mathrm{MWh}$ can be obtained.

The largest price difference between both extension cases can be observed in the region close to the Dutch border which is due to the highly concentrated location of new plants. This extension pattern with nearly all plants located close to an interconnection towards the Netherlands, and one plant at the interconnection to Austria shows that the actual generation is needed to counteract network problems and allow a better utilization of scarce transmission capacities. The price pattern in Germany is only slightly altered, but prices in the Benelux drop about $3 € / \mathrm{WMh}$ on average.

In a last calculation the extension pattern of the welfare case is altered and new plants are also allowed to be located in neighboring countries. In this EU scenario a significant price reduction compared to all other cases can be observed. The price level is about $19 € / \mathrm{MWh}$ lower on average and $26 € / \mathrm{MWh}$ lower during peak times compared to the 2007 benchmark case (Table 3). The locational price pattern now shows a price convergence not only within Germany but within the whole market region. Price differences are largely reduced. The plant locations of this scenario show that the projected extensions for Germany are more efficient if placed outside of Germany. With five new plants placed in Belgium the major congestion problem of the network is resolved leaving room for other plant locations.

Contrary to the other scenarios we observe plant extension in Poland and France. The latter is due to the fact that the relieved network congestion makes France the most expensive node of the system whereas before it always was amongst the cheapest. The extensions in Poland are most likely due to the impact of wind energy along the north east region of Germany. Similar to the Benelux border the increased wind injection without local demand results in power flows towards demand centers crossing national borders. The main difference to the Benelux is the fact that prices in East Germany and Poland are set by coal fired units thus no large price divergence is observed along the interconnection. The additional coal units in Poland allow a better utilization of the scare transmission capacity and thus of wind sources in East Germany. Although, the marginal plants and thus the prices do not differ the overall generation costs can be lowered.

Beside extensions in neighboring countries still five plants are placed within Germany. However, none of them close the projected locations. They are all clustered in the north of Bavaria. This location allows supplying demand centers in the South and West Germany, and simultaneously a better utilization of the interconnection to East Germany with its large share of lignite and wind generation.

Comparing the price outcomes of those seven cases we can conclude that a separated, national market representation of the Germany electricity market is insufficient to cover the interactions between 
demand and generation in an interlinked European network. The resulting price level is too low as congestion outside of Germany is not accounted for.

\subsection{Discussion}

Comparing the overall generation costs of all scenarios and cases it appears that a consideration of network constraints is welfare improving (Table 3). This is particularly striking in the EU scenario where a saving of about 3 billion Euros per year can be achieved by reallocating the planned plant locations. As the modeled plant extensions are solely based on existing projects this gain can be achieved without additional costs.

The consideration of network restrictions (welfare case compared to base case) provides savings in the range of $1 \%$ or about 200 million Euros per year. However, the resulting price reductions are rather low. The different plant locations of the scenarios show that the projected sites within Germany are not optimal with respect to welfare maximization. However, the obtainable difference by reallocating the plants in Germany is rather low. Thus from a national perspective the projected locations are a reasonable outcome. However, if the national perspective is overcome and a fully integrated European market could be postulated the projected plants can all be placed more efficiently resulting in a significant welfare gain.

The model bears shortcomings with respect to the possibilities of plant locations as all available network nodes are assumed to be suited for new power plants. Furthermore, fuel restrictions for gas plants are not considered as the underlying natural gas network is not regarded and coal is considered without additional transportation costs for southern network nodes. Thus the calculated results represent an upper boundary of welfare gains and price reductions.

Table 3: Comparison of scenario results

\begin{tabular}{lccccccc}
\hline Market scenario: & \multicolumn{3}{c}{ Germany } & \multicolumn{3}{c}{ Market Coupling } & EU \\
\hline Extension case & $\begin{array}{c}\text { Bench } \\
\text { mark }\end{array}$ & Base & Welfare & $\begin{array}{c}\text { Bench } \\
\text { mark }\end{array}$ & Base & Welfare & Welfare \\
\hline $\begin{array}{l}\text { Average price } \\
\text { [€/MWh] }\end{array}$ & & & & 53.12 & 43.16 & 42.46 & 35.38 \\
$\begin{array}{l}\text { Average daytime price } \\
\text { [€/MWh] }\end{array}$ & & & & 62.60 & 46.90 & 45.75 & 36.50 \\
$\begin{array}{l}\text { Average price in } \\
\text { Germany [€/MWh] }\end{array}$ & 48.00 & 42.28 & 41.22 & 53.63 & 43.28 & 42.54 & 35,67 \\
$\begin{array}{l}\text { Average daytime price } \\
\text { in Germany [€/MWh] }\end{array}$ & 53.23 & 44.32 & 42.99 & 63.33 & 47.15 & 45.88 & 36,89 \\
Generation costs [bn €/a] & 15.82 & 15.15 & 14.97 & 43.70 & 40.16 & 39.93 & 37.21 \\
\hline $\begin{array}{l}\text { Number of } \\
\text { new plants in: }\end{array}$ & & & & & & & \\
Baden-Württemberg & & 1 & 6 & & 1 & 1 & \\
$\begin{array}{l}\text { Bavaria } \\
\text { Lower Saxony }\end{array}$ & 1 & 2 & & 1 & 1 & 5 \\
$\begin{array}{l}\text { North Rhine-Westphalia } \\
\text { Rhineland-Palatinate }\end{array}$ & 4 & 4 & & 4 & 6 & \\
$\begin{array}{l}\text { Belgium } \\
\text { France }\end{array}$ & 6 & 1 & & 6 & & \\
Poland & 1 & & & & & \\
\hline
\end{tabular}




\section{Conclusion}

This paper investigates the question of economic efficient placing of generation investments and the influence of market integration. Different locations for power plant placing in Germany and its surrounding countries are modeled using scenario analysis. The 2007 scenario is calculated without any extensions. Building upon this we calculate the outcomes for two more scenarios comparing existing investment plans to the placing under an economic efficient regime. In all scenarios, average market prices decrease significantly if there is generation investment. When comparing the different states of market integration, we find that with an increasing integration average prices fall significantly and converge throughout the interconnected network. Furthermore plant locations take place in order to utilize the network more efficiently, and to satisfy international demand by locating a part of the expected power plants near to foreign demand centers. Hence, cross-border congestion can be relieved particularly between the German and Benelux borders. Considering the problems of cross-border congestion and lacking market integration within the $\mathrm{EU}$, this paper demonstrates that great benefits for consumers and producers can be created when physical network restriction are taken into account within a real integrated market.

\section{References}

Belpex (2009): Market Coupling. Available: http://www.belpex.be/index.php?id=4. Accessed: 19 January 2009.

Brandstetter, Ernst (2007): Strom für die Zukunt. In: VEÖ Journal, Mai/07.

Bushnell, James, and Steven Stoft (1996): Transmission and Generation Investment in a Competitive Electric Power Industry. Working Paper PWP-030, University of California Energy Institute, Berkeley, CA, USA.

CEZ (2007): The Leader in Power Markets of Central and Southeastern Europe, Presented at the International Utility Conference, March 4-7, 2007, London, UK. Available: http://www2.eei.org/meetings/nonav_2007-03-04-dh/CEZ.pdf. Accessed: 19 January 2009.

Ding, Feng, and J. David Fuller (2005): Nodal, Uniform, or Zonal Pricing: Distribution of Economic Surplus. In: IEEE Transactions on Power Systems, 20, 875-882.

DWD. 2005. "Datenabgabe 439/05, Wind Speed Information about 8 Stations." German Weather Service (DWD).

Ehrenmann, Andreas, and Yves Smeers (2005): Inefficiencies in European Congestion Management Proposals. In: Utilities Policy, 13, 135-152.

Elia (2008): Forecast Evolution of the Generation Capacity. Available: http://www.elia.be/repository/pages/cf8194b2a73246eaacf47c2db686d73d.aspx. Accessed: 11 August 2008.

Hogan, William W. (1992): Contract Networks for Electric Power Transmission. In: Journal of Regulatory Economics, 4, 211-242. 
Hogan, William W. (1999): Transmission Congestion: The Nodal-Zonal Debate Revisited. Mimeo, Center for Business and Government, Harvard University, Cambridge, MA, USA. Available: http://ksghome.harvard.edu/ whogan/nezn0227.pdf. Accessed: 19 January 2009.

House, Joshua C. (2004): The Polish Electricity Market Investment Context. Program on Energy and Sustainable Development, Working Paper 31, Stanford University.

Ishii, Jun, and Jingming Yan (2004): Investment under Regulatory Uncertainty: U.S. Electricity Generation Investment Since 1996. Working Paper CSEM WP 127, University of California Energy Institute, Berkeley, CA, USA.

Joskow, Paul L. (2008): Lessons Learned from Electricity Market Liberalization. In: The Energy Journal, Special Issue.

Joskow, Paul, and Jean Tirole (2005): Merchant Transmission Investment. In: The Journal of Industrial Economics, 53(2), 233-264.

Knight, Sara (2006): 31.4 GW Planned for Germany. In: Platts (2006): Power in Europe. Issue 486.

Leuthold, Florian, Hannes Weigt, and Christian von Hirschhausen (2008): ELMOD - A Model of the European Electricity Market. Working Paper WP-EM-00, Dresden University of Technology, Dresden, Germany.

Meeus, Leonardo (2006): Power Exchange Auction Trading Design. Ph.D. Thesis, Catholic University of Leuven, Belgium. Available: http://www.esat.kuleuven.be/electa/publications/ fulltexts/pub_1581.pdf. Accessed: 19 January 2009.

Murphy, Frederic H., and Yves Smeers (2005): Generation Capacity Expansion in Imperfectly Competitive Restructured Electricity Markets. In: Operations Research, 53, 646-661.

Nordpool (2009): Implicit Auction. Available: http://www.nordpoolspot.com/PowerMaket/TheNordic-model-for-a-liberalised-power-market/Implicit-auction/. Accessed: 19 January 2009.

Peréz-Arriaga, Ignacio, and Luis Olmos (2006): Compatibility of Investment Signals in Distribution, Transmission, and Generation. In Francois Lévêque (ed.) (2006): Competitive Electricity Markets and Sustainability. Cheltenham, UK, and Northampton, MA, USA, Eward Elgar, pp. 230-288.

Pokharel, Shaligram, and Kumaraswamy Ponnambalam (1997): Investment Planning for Electricity Generation Expansion. In: International Journal of Energy Research, 21, 185-194.

Rious, Vincent, Philippe Dessante, and Yannick Perez (2008): Is Combination of Nodal Pricing and Average Participation Tariff the Best Solution to Coordinate the Location of Power Plants with Lumpy Transmission Investments? Paper presented at the Conference on "The Economics of Energy Markets", June 20-21, 2008, Toulouse, France.

Schweppe, Fred C., Michael C. Caramanis, Richard D. Tabors, and Roger E. Bohn (1988): Spot Pricing of Electricity. Boston, Kluwer.

Smeers, Yves (2006): Long-Term Locational Prices and Investment Incentives in the Transmission of Electricity. In Francois Lévêque (ed.) (2006): Competitive Electricity Markets and Sustainability. Cheltenham, UK, and Northampton, MA, USA, Eward Elgar, pp. 187-229. 
Stigler, Heinz, and Christian Todem (2005): Optimization of the Austrian Electricity Sector (Control Zone of VERBUND APG) under the Constraints of Network Capacities by Nodal Pricing. In: Central European Journal of Operations Research, 13, 105-125.

Slingerland, Stephan, Christoph Tönjes, and Jacques de Jong (2006): The European Electricity Market: Some Trends and Consequences for Investments in the Netherlands. Clingendael International Energy Programme, CIEP 04/2006.

VSE (2006): Vorschau 2006 auf die Elektrizitätsversorgung der Schweiz im Zeitraum bis 2035/2050. Verband Schweizerischer Elektrizitätsunternehmen.

UCTE. 2006. "Consumption Data." Retrieved January 19, 2007, from: http: //www.ucte.org/statistics/onlinedata/consumption/e default.asp.

Zoettl, Georg (2008): Investment Decisions in Liberalized Electricity Markets: A Framework of Peak Load Pricing with Strategic Firms. Paper presented at the Conference on "The Economics of Energy Markets", June 20-21, 2008, Toulouse, France. 


\section{Annex I}

Figure 2: Average prices and plant locations: scenario Germany
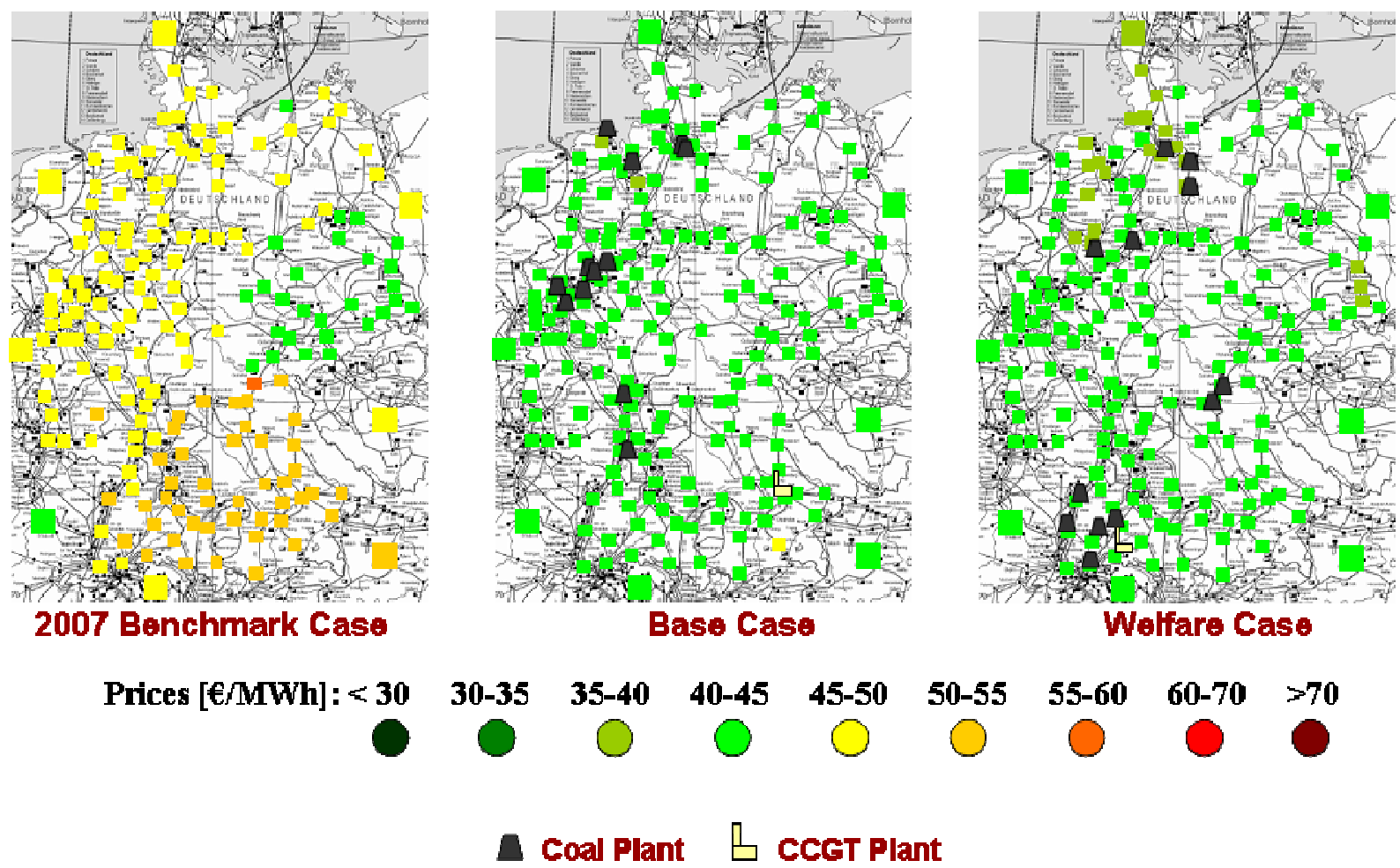

Figure 3: Average prices and plant locations: scenario Market Coupling
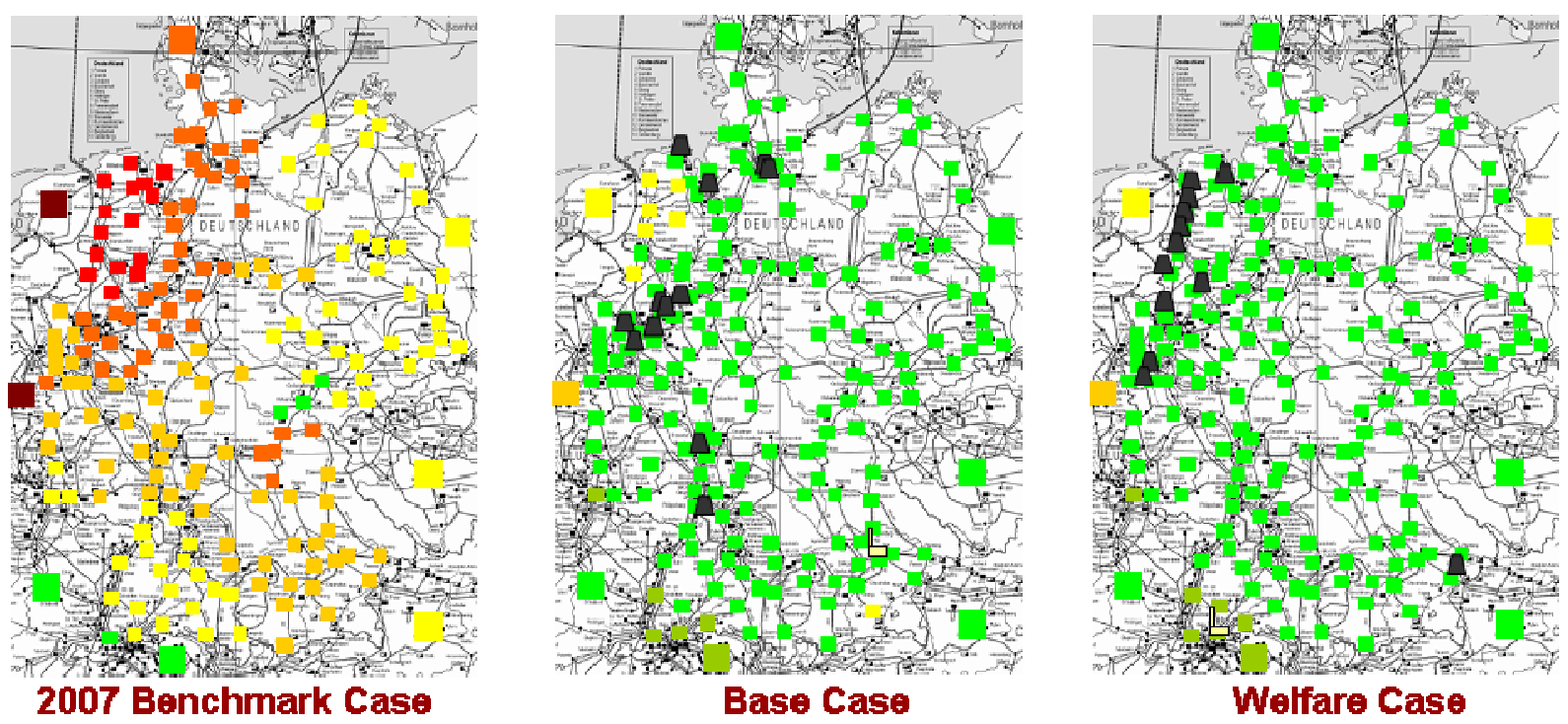

Prices $[€ / \mathrm{MWh}]:<\mathbf{3 0}$

30-3

$35-40$

40-45 $\quad 45-50$

$50-55$

55-60

$60-70>70$

a coal Plant \& ccGt Plant 
Figure 4: Daytime prices and plant locations: scenario Germany
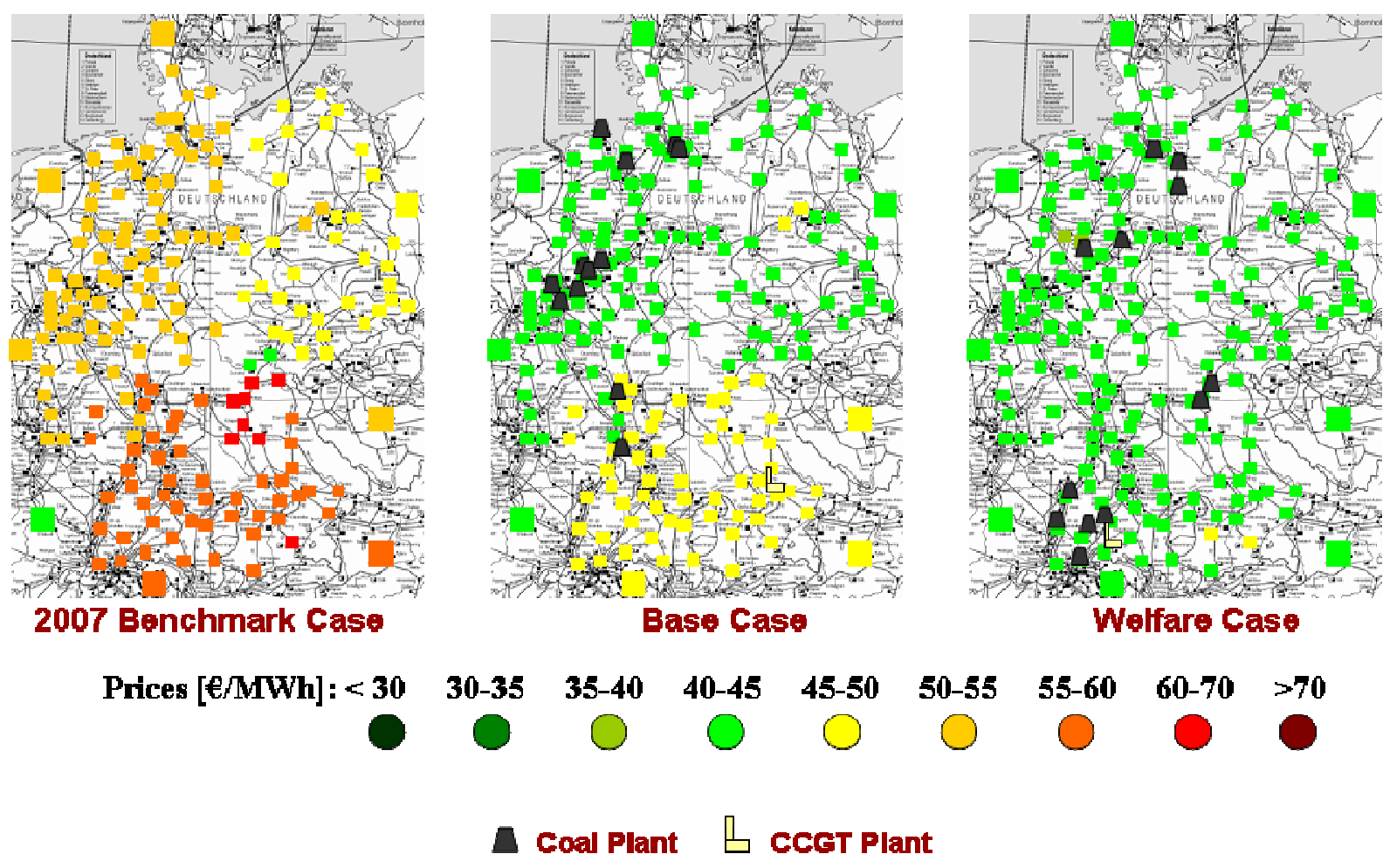

Figure 5: Daytime prices and plant locations: scenario Market Coupling
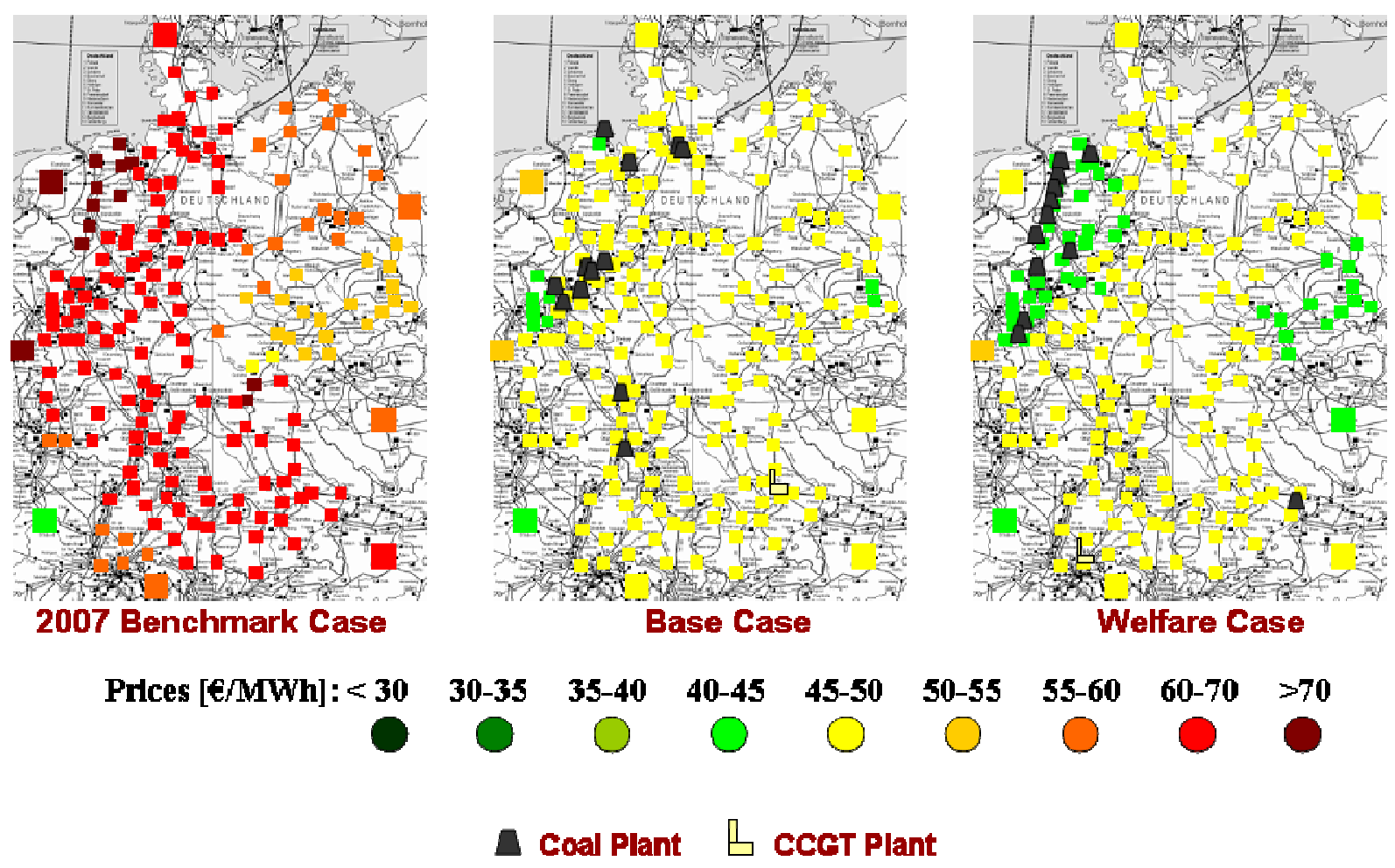
Figure 6: Average and daytime prices and plant locations: scenario $E U$
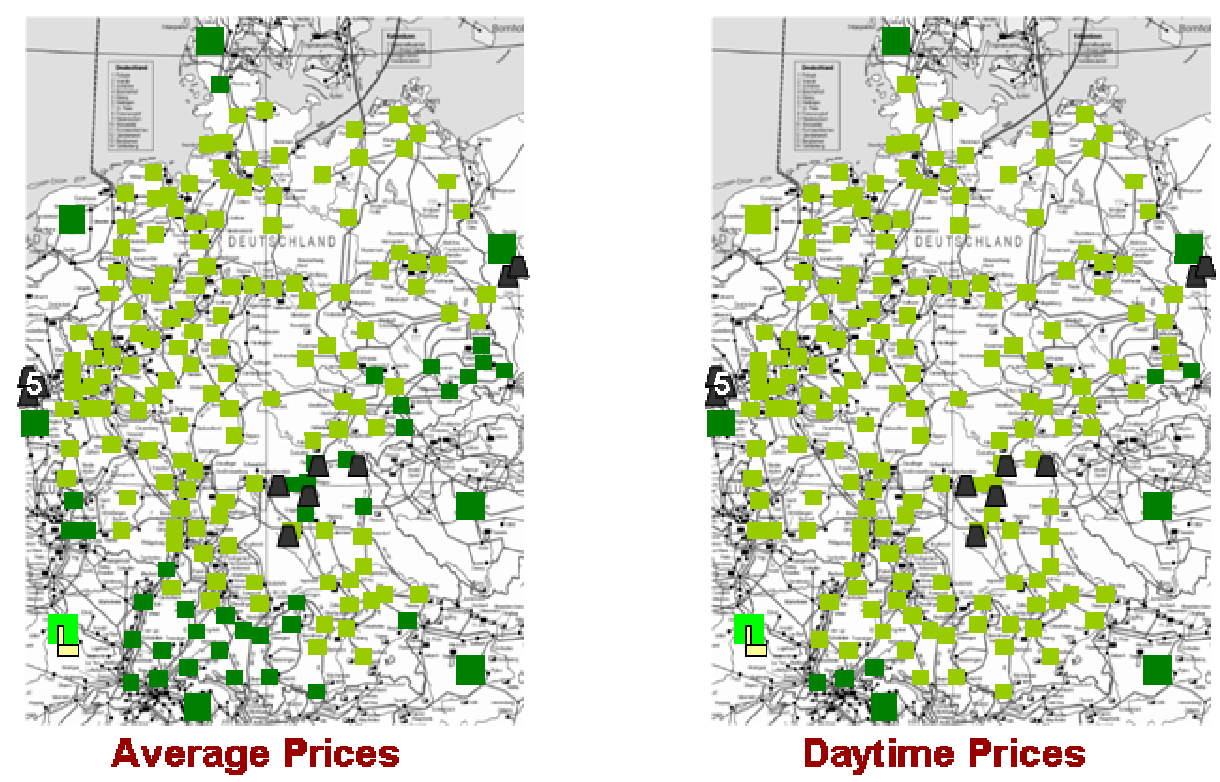

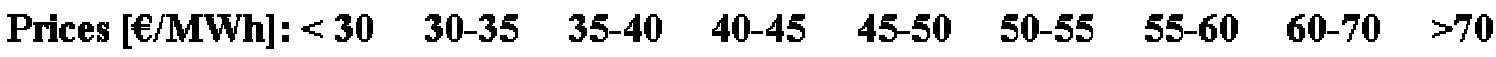

A coal Plant $\quad$ G coT Plant 